Journal of Animal and Veterinary Advances 9 (21): 2671-2673, 2010

ISSN: $1680-5593$

(C) Medwell Journals, 2010

\title{
First Report of Heterakis gallinarum in Gould's Wild Turkey (Meleagris gallopavo mexicana) in Mexico
}

\author{
H. Martinez Guerrero Jose, E. Pereda Solis Martin, \\ Rosales Alferez Federico and M. Herrera Casio Hector \\ Facultad de Medicina Veterinaria y Zootecnia de la, \\ Universidad Juárez del Estado de Durango, Durango, Dgo. 34000, Mexico
}

\begin{abstract}
In the 2009 hunting season in the state of Durango, Mexico we obtained 21 Gastro Intestinal Tracts (GIT) of adult male Wild Turkeys (Meleagris gallopavo mexicana, Gould, 1856). Analysis of the each GIT resulted in the recovery of 2,549 adult parasites of which $59.4 \%$ were Nematodes of the order Ascaridida and species Heterakis gallinarum. We found 1,511 H. gallinarum in the large intestine, 99\% of which were in the caecum and $1 \%$ in the colon. Many researchers have reported the presence of $H$. gallinarum in different subspecies of Wild Turkey but never in the Gould subspecies. Members of the genus Heterakis are known to be found only in the caeca of birds are small in size $(7-13 \mathrm{~mm})$, whitish or pale in color and lay eggs that are on average, $65-80 \mu$ in length. It is the first record of Heterakis gallinarum in wild Turkey in Mexico.
\end{abstract}

Key words: Heterakis gallinarum, Meleagris gallopavo, gastrointestinal parasites, whitish, nematods, ascaridida

\section{INTRODUCTION}

About 25 species of nematodes have been found in the Wild Turkey but only a few of them are considered part of the host's normal helminth fauna, the presence and prevalence of which varies according to geographic distribution (Davison and Wentworth, 1992). Included in the normal fauna of the Wild Turkey are Ascaridia dissimilis, A. galli, Capillaria caudinflata and $C$. obsignata in the small intestines, Heterakis gallinarum and Trichostrongylus tenuis in caeca and Dispharnix nasuta and Cyrne colini in the proventricle.

The majority of species are not considered pathogens nor are they associated with sicknesses in the Turkey (Hon et al., 1975) nonetheless, H. gallinarum is important in the health of Wild Turkey populations as it is a carrier of Histomonas meleagridis, a protozoan that can cause death in Turkeys (Prestwood et al., 1973; Hurst and Couvillion, 1997; Hurst, 1980).

Nematodes have a direct cycle and practice spoliation, histophagia and hematophagia causing congestion, hemorrhagic enteritis, hepatomegaly and splenomegaly (Cordero et al., 2000).

Case report: The researchers collected 21 gastrointestinal tracts (GIT's) from adult males of Gould's Wild Turkey in the months of April and May during the 2007 hunting season in the Presidente Salvador Allende Wildlife Management and Conservation Area (UMA, the Spanish acronym) located at $25^{\circ} 06^{\circ} 35^{\prime} ' \mathrm{~N}$ and $104^{\circ} 55^{\prime} 05^{\prime \prime} \mathrm{W}$ in the county and state of Durango, Mexico (Registro SEMARNAT, DGVS-EX 2939-DGO).

We tied off GIT's at the distinct sections that make up the bird's digestive apparatus in order to avoid movement of parasites during handling of the sample and therefore, be able to establish relationships between location in the gut and the presence of different species of gastrointestinal parasites (Olsen, 1974). In this manner, we analyzed each gut segment and recovered adult parasites found in each of them.

We washed intestinal contents with physiological saline solution in a petri dish and used a stereoscope and slides with a lactophenol solution (lactic acid, phenol and glycerin) to count and identify parasites (Pritchard and Kruse, 1982).

\section{RESULTS AND DISCUSSION}

We recovered 2,540 adult parasites from the 21 GIT samples of Gould's Wild Turkey, 59.5\% (1,511 individuals) of which were $H$. gallinarum. Sixteen of the 21 samples contained this parasite, all in the large intestine and almost exclusively in the caecum ( $99 \%$ caecum, $1 \%$ colon).

Corresponding Author: H. Martinez Guerrero Jose, Facultad de Medicina Veterinaria y Zootecnia de la, Universidad Juarez del Estado de Durango, Durango, Dgo. 34000, Mexico 


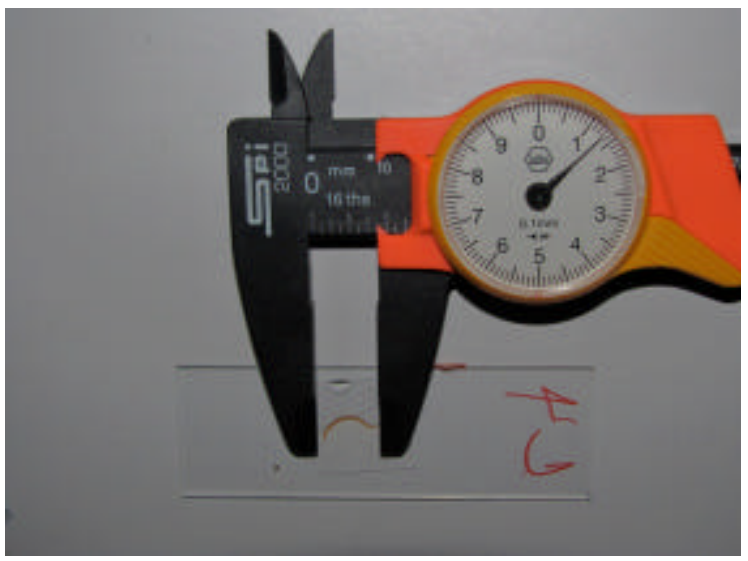

Fig. 1: Measuring an adult individual of $H$. gallinarum

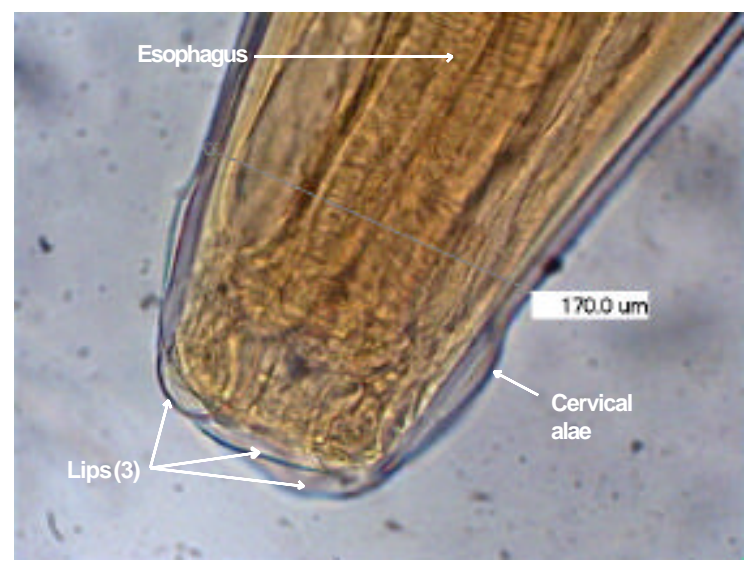

Fig. 2: Oocyst of H. gallinarum (Moticam, 10x)

Many researchers report findings of $H$. gallinarum in different subspecies of Wild Turkey in the United States but not in the Gould's subspecies (Prestwood et al., 1973; Hon et al., 1975) as cited by Davison and Wentworth, 1992) with a greater prevalence in spring than fall (McJunkin et al., 2003). Classification according to Olsen (1974):

\section{Class Secernentea}

Order Ascaridida

\section{Family Heterakidae Genus Heterakis}

\section{Species Heterakis gallinarum, Shrank 1788}

Members of the genus Heterakis are known to be found only in the caeca of birds (Anderson, 2000) are small in size $(7-13 \mathrm{~mm})$, whitish or pale in color (Atkinson et al., 2008) (Fig. 1) and lay eggs that are on average, $65-80 \mu$ in length (Fig. 2). Figure 3 show the buccal capsule where 3 lips are visible along with the

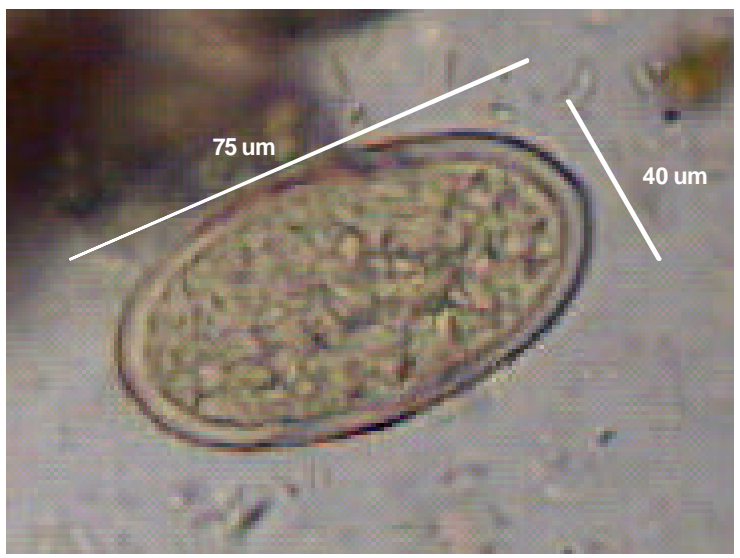

Fig. 3: Buccal capsule of H. gallinarum (Moticam, 10x)

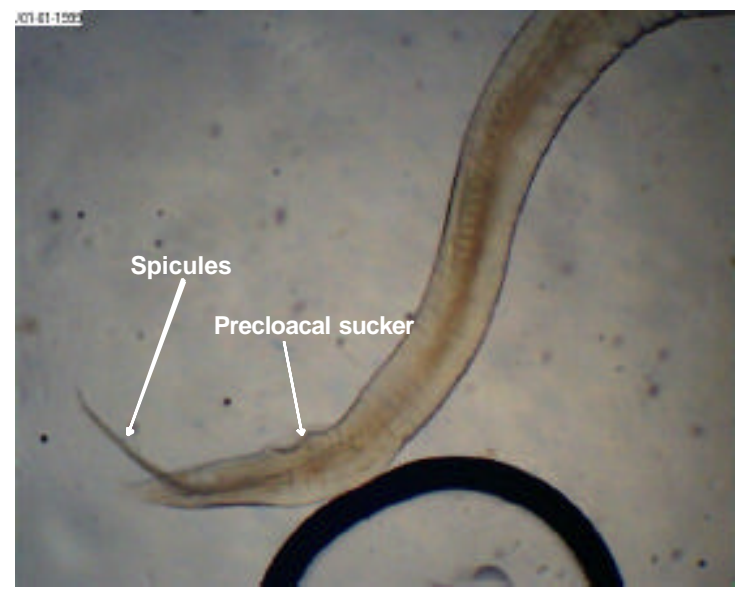

Fig. 4: Caudal portion of H. gallinarum (Moticam, 10x)

cervical alae and esophagus (Anderson et al. 2009). Figure 4 shows the spicules and precloacal sucker which are distinctive features of $H$. gallinarum (Olsen, 1974).

\section{CONCLUSION}

The researchers identified the presence of $H$. gallinarum in Gould's Wild Turkey in the Sierra Madre Occidental of Mexico representing the first report of this species in these hosts. This finding is significant in that H. gallinarum can cause Histomaniasis in its host, a disease with potentially grave consequences for populations of turkeys. However, necropsies revealed no liver damage characteristic of this disease.

\section{REFERENCES}

Anderson, R.C., 2000. Nematode Parasites of Vertebrates. Their Development and Transmission. CABI Publishing, UK., pp: 650. 
Anderson, R.C., A. Chabaud and S. Willmott, 2009. Keys to the Nematode Parasites of Vertebrates. 1st Edn., CABI Publishing, UK., pp: 480.

Atkinson, C.T., N.J. Thomas and D.B. Hunter, 2008. The Parasitic Diseases of Wild Birds. Wiley-Blackwell, Iowa, USA., pp: 592.

Cordero, C., F.A. Rojo, A.R. Martinez, C. Sanchez and S. Hernandez et al., 2000. Parasitologia Veterinaria. McGraw-Hill Interamericana, Madrid, Espana, ISBN: 84-486-0236-6, pp: 982.

Davison, W. and E.J. Wentworth, 1992. Population Influences: Diseases and Parasites. Chapter 8. In: The Wild Turkey: Biology and Management, Dickson, J.D. (Ed.). Stackpole Books, Harrisburg, PA., pp: 480.

Hon, L.T., D.J. Forrester and L.E. Jr. Williams, 1975. Helminths of wild turkeys in Florida. Proc. Helminthol. Soc. Washington, 45: 119-127.

Hurst, G.A. and E. Couvillion, 1997. Problems pertaining to the wild Turkey. In Mississippi's Wildlife Monarch, the Wild Turkey. The Mississippi Chapter of The National Wild Turkey Federation, Natchez, MS., pp: 23-33.
Hurst, G.A., 1980. Histomoniasis in wild turkeys in Mississippi. J. Wildl. Dis., 16: 357-358.

McJunkin, J.W., R.D. Applegate and D.A. Zelmer, 2003. Enteric helminths of juvenile and adult wild turkeys (Meleagris gallopavo) in eastern Kansas. Avian Dis., 47: 1481-1485.

Olsen, W.O., 1974. Animal Parasites: Their Life Cycle and Ecology. University Park Press, Baltimore, Maryland, ISBN: 0-486-65126-6, pp: 562.

Prestwood, A.K., F.E. Kellogg and G.L. Doster, 1973. Parasitism and Disease Among Southestern Wild Turkey. In: Wild Turkey Management: Current Problems and Programs, Sanderson, G.C. and H.C. Schultz (Eds.). University of Missouri Press, USA, ISBN-13: 9780826201331 , pp: $27-32$.

Pritchard, M.H. and G.O.W. Kruse, 1982. The collection and preservation of animal parasites. Am. J. Trop. Med. Hyg., 32: 433-434. 